\title{
Lanthanum (La) improves growth, yield formation and 2-acetyl-1-pyrroline biosynthesis in aromatic rice (Oryza sativa L.)
}

Haowen Luo ${ }^{1,2,3}$, Yulin Chen ${ }^{4}$, Longxin He $\mathrm{e}^{1,2,3}$ and Xiangru Tang $1,2,3^{*}$ (D)

\begin{abstract}
Background: Lanthanum ( $\mathrm{La}$ ) is a rare earth element that can influence plant growth and development. However, the effect of La on growth, yield formation and 2-acetyl-1-pyrroline (2-AP, a key compound responsible for the aroma of rice) biosynthesis in aromatic rice (Oryza sativa L. subsp. japonica Kato) has not been reported. Therefore, the present study investigated the effects of La on growth, photosynthesis, yield formation and 2-AP biosynthesis in aromatic rice through three experiments.

Results: Two pot experiments and a two-year field trial were conducted with different rates of La application (20-120 $\mathrm{LaCl}_{3} \mathrm{mg} \mathrm{kg}^{-1}$ and $12 \mathrm{~kg} \mathrm{ha}^{-1} \mathrm{LaCl}_{3}$ ), and treatments without La application were used as controls. The results showed that the application of $\mathrm{LaCl}_{3}$ at 80 and $100 \mathrm{mg} \mathrm{kg}^{-1}$ and at $12 \mathrm{~kg} \mathrm{ha}^{-1}$ greatly increased the 2-AP content (by $6.45-43.03 \%$ ) in aromatic rice seedlings and mature grains compared with the control. The La treatments also increased the chlorophyll content, net photosynthetic rate and total aboveground biomass of rice seedlings. Higher antioxidant enzyme (superoxide, peroxidase, and catalase) activity was detected in the La treatments than in the control. The La treatments also increased the grain yield, grain number per panicle and seed-setting rate of aromatic rice relative to the control. Moreover, the grain proline and $y$-aminobutyric acid contents and the activity of betaine aldehyde dehydrogenase significantly decreased under the La treatment. The application of La to soil enhanced the activity of proline dehydrogenase by $20.62-56.95 \%$.
\end{abstract}

Conclusions: La improved the growth, yield formation and 2-AP content of aromatic rice and enhanced 2-AP biosynthesis by increasing the conversion of proline to 2-AP and decreasing the conversion of GABald to GABA.

Keywords: 2-acetyl-1-pyrroline, Aromatic rice, Lanthanum, Photosynthesis, Proline, Yield formation

\section{Background}

Aromatic rice (Oryza sativa L.) is well known worldwide for its characteristic aroma and is also highly desired by consumers, attracts premium prices in many international markets [1-4]. The aromatic compounds of aromatic rice are very complicated, and more than 200 volatile substances were detected in aromatic rice in

\footnotetext{
${ }^{*}$ Correspondence: tangxr@scau.edu.cn

${ }^{3}$ Guangzhou Key Laboratory for Science and Technology of Aromatic

Rice, Guangzhou 510642, China

Full list of author information is available at the end of the article
}

previous studies [5]. In recent years, it has been clearly established that 2-acetyl-1-pyrroline (2-AP) is the key flavor compound in aromatic rice that imparts its characteristic aroma [6, 7].

The biosynthesis of 2-AP in aromatic rice is a relatively clear process. Previous studies discovered that 2-AP formation is closely related to proline and $\gamma$-aminobutyric acid (GABA). In 2002, Yoshihashi et al. [8] revealed that proline is the nitrogen source for 2-AP through an isotope tracing test. Mo et al. [4] showed that 2-AP content is positively correlated with both the proline and GABA in aromatic rice. Chen et al. [9] demonstrated that 2-AP 
biosynthesis in aromatic rice is inhibited by the expression of the $B A D H 2$ gene; this gene encodes betaine aldehyde dehydrogenase (BADH) which catalyzes the conversion of $\gamma$-aminobutyl aldehyde (GABald) into GABA instead of 2-AP. Furthermore, the study of Mo et al. [10] indicated that the 2-AP in aromatic rice was transformed mainly from proline catalyzed by proline dehydrogenase (PDH).

Lanthanum (La) is one of the rare earth elements, a group that includes 17 elements with similar physical and chemical properties [11]. An earlier study showed that exogenous La significantly ameliorated copper toxicity in rice by reducing oxidative stress and increasing the chlorophyll content [12]. Liang et al. [13] discovered that La application remarkably enhanced plasma membrane $\mathrm{H}+$-ATPase activity in rice under acid rain stress. Liu et al. [14] indicated that exogenous $\mathrm{La}^{3+}$ induced regulation by the antioxidant system and affected the concentrations of hydrogen peroxide, superoxide anion, and malondialdehyde in rice roots. Wang et al. [15] also demonstrated that the combination of $\mathrm{LaCl}_{3}$ and acid rain substantially increased the net photosynthetic rate, stomatal conductance, Hill reaction activity and carboxylation efficiency of rice plants. Hence, it can be concluded that La has multiple effects on rice growth and development.

In 2016, Mo et al. [10] showed that supplementation with $\mathrm{La}$ in basic culture medium enhanced the activity of $\mathrm{PDH}$ and increased the 2-AP content in detached aromatic rice panicles in Vitro. La might have the ability to enhance 2-AP biosynthesis and the potential to be used in aromatic rice production to cultivate highly aromatic rice. However, no additional studies of the effects of $\mathrm{La}$ on aromatic rice growth performance have been published. Furthermore, the mechanism underlying the regulation of 2-AP formation under exogenous La application remains unexplored.

Therefore, the present study was conducted with the hypothesis that La could increase grain yield and 2-AP content in aromatic rice and with the objective of studying the mechanism underlying the effects of La on 2-AP biosynthesis in aromatic rice.

\section{Results}

Effects of La application on the performance of aromatic rice seedlings

The application of La to soil significantly influenced the 2-AP content of the aromatic rice seedlings (Fig. 1). Compared with CK, the La treatments (La2, La3 and La4 treatments) notably improved the 2 -AP content, by $11.10-41.01 \%$ and $11.10-23.38 \%$ for Meixiangzhan-2 and Xiangyaxiangzhan, respectively and the highest contents were recorded in the La3 and La4 treatments. In addition, we observed that the La5 treatments suddenly decreased 2-AP content for Meixiangzhan-2 and

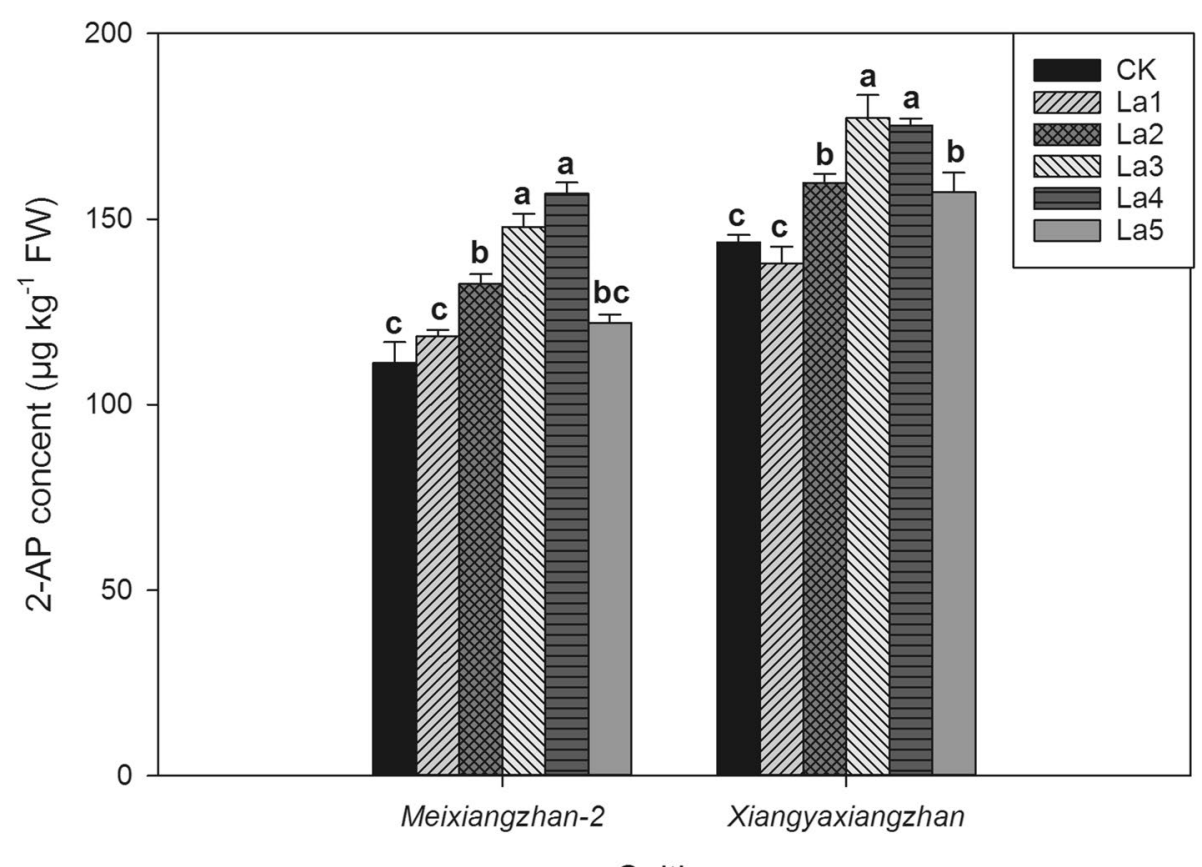

Cultivar

Fig. 1 Effects of different La treatments on the 2-AP content of aromatic rice seedlings. Values (means \pm SEs) of each treatment were obtained from three independent replications $(n=3)$. Different letters indicate significant differences among the treatments $(P<0.05$, least significant difference test) 
Xiangyaxiangzhan compared with that in the La3 and La4 treatments. This may have occurred because the content of La in soil in the La5 treatment exceeded the suitable range for fragrant rice and caused metal toxicity. Regarding seedling quality was concerned, the aromatic rice seedlings grown in La containing soils exhibited significant improvements in fresh weight, dry weight and stem diameter compared to those grown in soil without $\mathrm{La}$ (Table 1). In comparison with CK, La3 and La4 treatments exhibited significantly higher fresh weight (by $6.00-13.68 \%$ ), dry weight (by $5.98-19.45 \%$ ) and stem diameter by $(5.43-9.74 \%)$.

\section{Effects of La application on yield and yield related traits of aromatic rice}

The yield and yield-related traits of aromatic rice were affected by La application in both the second and third experiments (Table 2 \& Table 3). For Meixianghan-2 in the second experiment, compared with CK, the La80 treatment significantly increased the grain yield (by 12.22\%) while the La80 and La100 treatments significantly increased the grain number per panicle, seedsetting rates and total yield. For Xiangyaxiangzhan in the second experiment, compared with CK, the La80 and La100 treatments significantly increased the grain yield and total yield by $9.33-10.34 \%$ and $15.16-17.19 \%$, respectively. Compared with CK, the La100 and La80 treatments also significantly increased the grain number per panicle and seed-setting rate, respectively. In the field (the third Experiment), in comparison with CK, the La treatment significantly increased grain yield by $3.84-$ 10.73\% in 2018 and 2019 for both Meixiangzhan-2 and Xiangyaxiangzhan. Compared with CK, the La treatment also significantly increased the grain number per panicle, by $9.28-19.48 \%$. Moreover, slightly higher seed-setting rates were recorded in the La treatment than in CK in both years and for both cultivars. However, there was no significant difference between the CK and La treatments in the either effective panicle number or the 1000-grain weight.

\section{Effects of La application on the chlorophyll content of aromatic rice}

La application substantially increased the chlorophyll content of aromatic rice (Fig. 2 \& Fig. 3). In second experiment, there were no significant differences in SPAD values among all the treatments including $\mathrm{CK}$ at the tillering stage. At the booting stage, heading stage and grain-filling stage, the La80 and La100 treatments increased the SPAD value by $7.45-13.57 \%$ compared with CK, and at the maturity stage, slightly higher SPAD values were recorded in the La80 and La100 treatment than CK. In the third experiment, $4.32-18.95 \%$ higher SPAD values were recorded in the La treatment than in the CK treatment at the booting stage, heading stage and grain-filling stage. Compared with CK, the La treatment also slightly increased the SPAD value at the maturity stage.

\section{Effects of La application on the net photosynthetic rate of aromatic rice}

La application substantially improved the net photosynthetic rate of aromatic rice (Fig. 4 \& Fig. 5). In the second experiment, there were no significant differences in net photosynthetic rate among all the treatments including $\mathrm{CK}$ at the tillering stage. At the booting stage, heading stage and grain-filling stage, the La80 and

Table 1 Effect of different La treatments on the quality of aromatic rice seedlings

\begin{tabular}{|c|c|c|c|c|c|}
\hline Cultivar & Treatment & Fresh weight (mg) & Dry weight (mg) & Plant Height (cm) & Stem diameter $(\mathrm{mm})$ \\
\hline \multicolumn{6}{|c|}{ Meixiangzhan-2 } \\
\hline & CK & $168.37 \pm 5.61 b$ & $27.63 \pm 5.94 b$ & $20.68 \pm 0.94 b$ & $2.20 \pm 0.34 b c$ \\
\hline & La1 & $164.23 \pm 1.74 b$ & $27.13 \pm 6.33 b$ & $21.52 \pm 0.13 b$ & $2.14 \pm 1.33 b c$ \\
\hline & La2 & $168.60 \pm 2.64 b$ & $27.14 \pm 4.53 b$ & $21.45 \pm 0.87 b$ & $2.11 \pm 0.68 c$ \\
\hline & La3 & $178.47 \pm 3.52 \mathrm{ab}$ & $33.00 \pm 2.40 \mathrm{a}$ & $26.29 \pm 0.46 a$ & $2.39 \pm 1.17 a$ \\
\hline & La4 & $189.87 \pm 3.08 \mathrm{a}$ & $31.37 \pm 4.43 a$ & $25.15 \pm 0.78 a$ & $2.32 \pm 0.98 a$ \\
\hline & La5 & $169.00 \pm 2.22 b$ & $27.55 \pm 4.72 b$ & $21.48 \pm 1.32 b$ & $2.22 \pm 0.58 b$ \\
\hline \multicolumn{6}{|c|}{ Xiangyaxiangzhan } \\
\hline & CK & $137.20 \pm 1.95 b$ & $25.02 \pm 2.21 \mathrm{~cd}$ & $24.54 \pm 0.98 a b$ & $1.85 \pm 0.80 c$ \\
\hline & La1 & $135.80 \pm 4.43 b$ & $24.29 \pm 6.81 d$ & $23.55 \pm 0.11 b$ & $1.97 \pm 1.33 a b$ \\
\hline & La2 & $136.33 \pm 2.48 b$ & $26.67 \pm 1.63 b$ & $24.51 \pm 0.91 a b$ & $1.90 \pm 1.12 b c$ \\
\hline & La3 & $154.73 \pm 6.12 \mathrm{a}$ & $29.67 \pm 1.69 a$ & $25.35 \pm 0.16 a b$ & $2.03 \pm 0.04 a$ \\
\hline & La4 & $155.97 \pm 1.87 a$ & $26.52 \pm 4.44 b c$ & $26.98 \pm 0.30 a$ & $2.03 \pm 1.02 \mathrm{a}$ \\
\hline & La5 & $137.10 \pm 5.25 b$ & $25.16 \pm 6.43 \mathrm{bcd}$ & $25.41 \pm 0.11 \mathrm{ab}$ & $1.95 \pm 0.34 a b c$ \\
\hline
\end{tabular}

Values (means $\pm S E s$ ) of each treatment were obtained from three independent replications $(n=3)$. Different letters indicate significant differences among the treatments $(P<0.05$, least significant difference test) 
Table 2 Effects of La application on grain yield, effective panicle number, grain number per panicle, seed-setting rate, 1000-grain weight and total yield of aromatic rice in the second experiment

\begin{tabular}{|c|c|c|c|c|c|c|c|}
\hline Cultivar & Treatment & $\begin{array}{l}\text { Grain yield (g } \\
\text { pot }^{-1} \text { ) }\end{array}$ & $\begin{array}{l}\text { Effective panicle } \\
\text { number per pot }\end{array}$ & $\begin{array}{l}\text { Grain number per } \\
\text { panicle }\end{array}$ & $\begin{array}{l}\text { Seed-setting rate } \\
(\%)\end{array}$ & $\begin{array}{l}\text { 1000-grain weight } \\
\text { (g) }\end{array}$ & $\begin{array}{l}\text { Total yield (g } \\
\text { pot }^{-1} \text { ) }\end{array}$ \\
\hline \multicolumn{8}{|c|}{ Meixiangzhan-2 } \\
\hline & CK & $53.46 \pm 2.18 b$ & $28.67 \pm 1.03 a$ & $133.12 \pm 0.39 c$ & $71.31 \pm 0.21 b$ & $19.92 \pm 0.03 a$ & $19.68 \pm 0.04 b$ \\
\hline & La40 & $56.32 \pm 1.01 a b$ & $27.00 \pm 2.84 a$ & $130.23 \pm 0.50 b c$ & $75.46 \pm 0.56 a$ & $20.08 \pm 0.02 \mathrm{a}$ & $18.63 \pm 0.02 b$ \\
\hline & La80 & $59.99 \pm 1.30 a$ & $27.67 \pm 0.81 a$ & $138.81 \pm 1.13 a b$ & $75.33 \pm 0.44 a$ & $19.86 \pm 0.03 a$ & $22.63 \pm 0.06 a$ \\
\hline & La100 & $58.08 \pm 0.65 a b$ & $29.67 \pm 1.93 a$ & $141.83 \pm 0.85 a$ & $72.24 \pm 0.22 b$ & $20.18 \pm 0.03 a$ & $22.31 \pm 0.04 a$ \\
\hline \multicolumn{8}{|c|}{ Xiangyaxiangzhan } \\
\hline & CK & $53.94 \pm 1.74 b c$ & $28.33 \pm 1.69 a$ & $129.83 \pm 0.36 b$ & $71.40 \pm 0.39 b$ & $20.47 \pm 0.05 a$ & $21.35 \pm 0.07 b$ \\
\hline & La40 & $53.17 \pm 0.38 c$ & $26.67 \pm 2.44 a$ & $137.03 \pm 0.44 a b$ & $72.67 \pm 0.36 a b$ & $20.10 \pm 0.03 a$ & $22.09 \pm 0.02 b$ \\
\hline & La80 & $59.52 \pm 1.71 a$ & $28.67 \pm 2.16 \mathrm{a}$ & $135.95 \pm 0.42 a b$ & $75.04 \pm 0.28 a$ & $20.08 \pm 0.04 a$ & $24.89 \pm 0.02 \mathrm{a}$ \\
\hline & La100 & $58.97 \pm 1.35 a b$ & $28.33 \pm 2.59 a$ & $140.75 \pm 0.97 a$ & $73.49 \pm 0.73 a b$ & $20.07 \pm 0.01 a$ & $25.36 \pm 0.04 a$ \\
\hline
\end{tabular}

Values (means \pm SEs) of each treatment were obtained from three independent replications $(n=3)$. Different letters indicate significant differences among the treatments $(P<0.05$, least significant difference test)

La100 treatments improved the net photosynthetic rate by $7.45-14.08 \%$ compared with that in CK, and at the maturity stage, slightly higher net photosynthetic rates were recorded in the La80 and La100 treatments than in CK. In the third experiment, 4.98-18.41\% higher net photosynthetic rates were recorded in the La treatment than CK at the booting stage, heading stage and grainfilling stage. Compared with $\mathrm{CK}$, the La treatment also slightly improved net photosynthetic rate at the maturity stage.

\section{Effects of La application on dry matter accumulation in aromatic rice}

La application remarkably enhanced the dry matter accumulation in aromatic rice in the field experiment
(Fig. 6). For Meixangzhan-2 in 2018, 14.33, 18.41, 17.69 and $16.83 \%$ higher total aboveground biomasses were recorded in the La treatment than in CK at the booting stage, heading stage, grain-filling stage and maturity stage, respectively. For Xiangyaxiangzhan in 2018, 8.74, 11.76, 10.79 and $11.66 \%$ higher total aboveground biomasses were recorded in the La treatment than in CK at the booting stage, heading stage, grain-filling stage and maturity stage, respectively. For Meixiangzhan-2 in 2019 , compared with CK, the La treatment significantly increased the total aboveground biomass by 11.69 , $18.15,21.15$ and $22.14 \%$ in the four growth stages, respectively; for Xiangyaxiangzhan in 2019, compared with CK, the La treatment significantly increased the total aboveground biomass by 18.12, 20.53, 20.96 and $19.40 \%$ in the four growth stages, respectively.

Table 3 Effects of La application on grain yield, effective panicle number, grain number per panicle, seed-setting rate and 1000-grain weight of aromatic rice in the third experiment

\begin{tabular}{|c|c|c|c|c|c|c|c|}
\hline Year & Cultivar & Treatment & $\begin{array}{l}\text { Grain yield (g } \\
\text { pot }^{-1} \text { ) }\end{array}$ & $\begin{array}{l}\text { Effective panicle } \\
\text { number per pot }\end{array}$ & $\begin{array}{l}\text { Grain number per } \\
\text { panicle }\end{array}$ & $\begin{array}{l}\text { Seed-setting rate } \\
\text { (\%) }\end{array}$ & $\begin{array}{l}\text { 1000-grain weight } \\
\text { (g) }\end{array}$ \\
\hline \multirow[t]{6}{*}{2018} & Meixiangzhan-2 & & & & & & \\
\hline & & CK & $5.14 \pm 0.09 b$ & $260.94 \pm 21.33 a$ & $132.91 \pm 7.69 b$ & $77.82 \pm 3.68 \mathrm{a}$ & $20.61 \pm 0.05 a$ \\
\hline & & La & $5.54 \pm 0.10 \mathrm{a}$ & $295.59 \pm 26.74 a$ & $158.80 \pm 5.16 a$ & $76.89 \pm 4.19 a$ & $20.69 \pm 0.04 a$ \\
\hline & Xiangyaxiangzhan & & & & & & \\
\hline & & CK & $4.95 \pm 0.18 b$ & $257.04 \pm 1.00 \mathrm{a}$ & $141.05 \pm 4.92 \mathrm{~b}$ & $77.96 \pm 1.25 a$ & $19.96 \pm 0.40 \mathrm{a}$ \\
\hline & & La & $5.14 \pm 0.17 a$ & $269.80 \pm 7.77 a$ & $154.14 \pm 7.45 a$ & $77.02 \pm 2.18 \mathrm{a}$ & $20.54 \pm 0.15 a$ \\
\hline \multirow[t]{6}{*}{2019} & Meixiangzhan-2 & & & & & & \\
\hline & & CK & $5.21 \pm 0.08 b$ & $260.24 \pm 5.13 a$ & $143.40 \pm 2.38 b$ & $77.12 \pm 0.89 a$ & $20.14 \pm 0.11 a$ \\
\hline & & La & $5.69 \pm 0.07 a$ & $287.22 \pm 13.00 \mathrm{a}$ & $158.88 \pm 3.08 a$ & $78.31 \pm 1.92 \mathrm{a}$ & $20.39 \pm 0.46 a$ \\
\hline & Xiangyaxiangzhan & & & & & & \\
\hline & & CK & $4.69 \pm 0.18 b$ & $267.97 \pm 22.61 a$ & $138.61 \pm 8.06 a$ & $78.46 \pm 1.47 a$ & $20.00 \pm 0.44 a$ \\
\hline & & La & $5.19 \pm 0.06 a$ & $288.07 \pm 11.59 a$ & $153.06 \pm 7.72 \mathrm{a}$ & $77.24 \pm 1.07 \mathrm{a}$ & $19.69 \pm 0.06 a$ \\
\hline
\end{tabular}

Values (means $\pm S E s$ ) of each treatment were obtained from three independent replications $(n=3)$. Different letters indicate significant differences among the treatments $(P<0.05$, least significant difference test) 

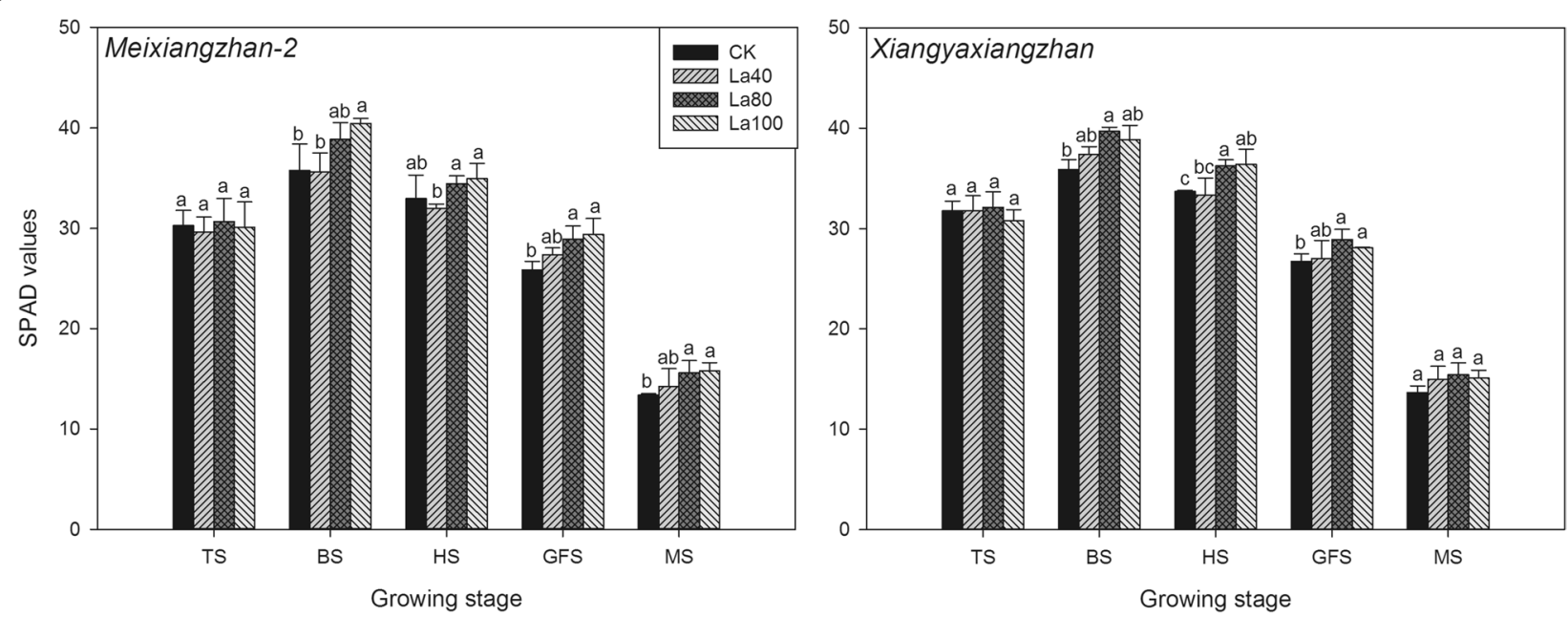

Fig. 2 Effects of different La treatments on the SPAD values of aromatic rice in the second experiment. TS: tillering stage; BS: booting stage: HS: heading stage: GFS: grain-filling stage; MS: Maturity stage. Values (means \pm SEs) of each treatment were obtained from three independent replications $(n=3)$. Different letters indicate significant differences among the treatments $(P<0.05$, least significant difference test)

Effects of La application on the activities of SOD, POD, and CAT and content of MDA in aromatic rice

As shown in Fig. 7, La application affected the MDA content and induced regulation in antioxidative enzyme (SOD, POD and CAT) activity. There was no significant difference between $\mathrm{CK}$ and the La treatment in the activities of SOD, POD, and CAT or the content of MDA at the tillering stage. However, compared with CK, the La treatment increased the activities of SOD, POD and CAT by $10.86-23.08 \%, 8.89-24.44 \%$ and $7.14-36.37 \%$, respectively, from the booting stage to the maturity stage. The MDA contents were $8.26-24.83 \%$ lower than in the La treatment than CK from the booting stage to the maturity stage.
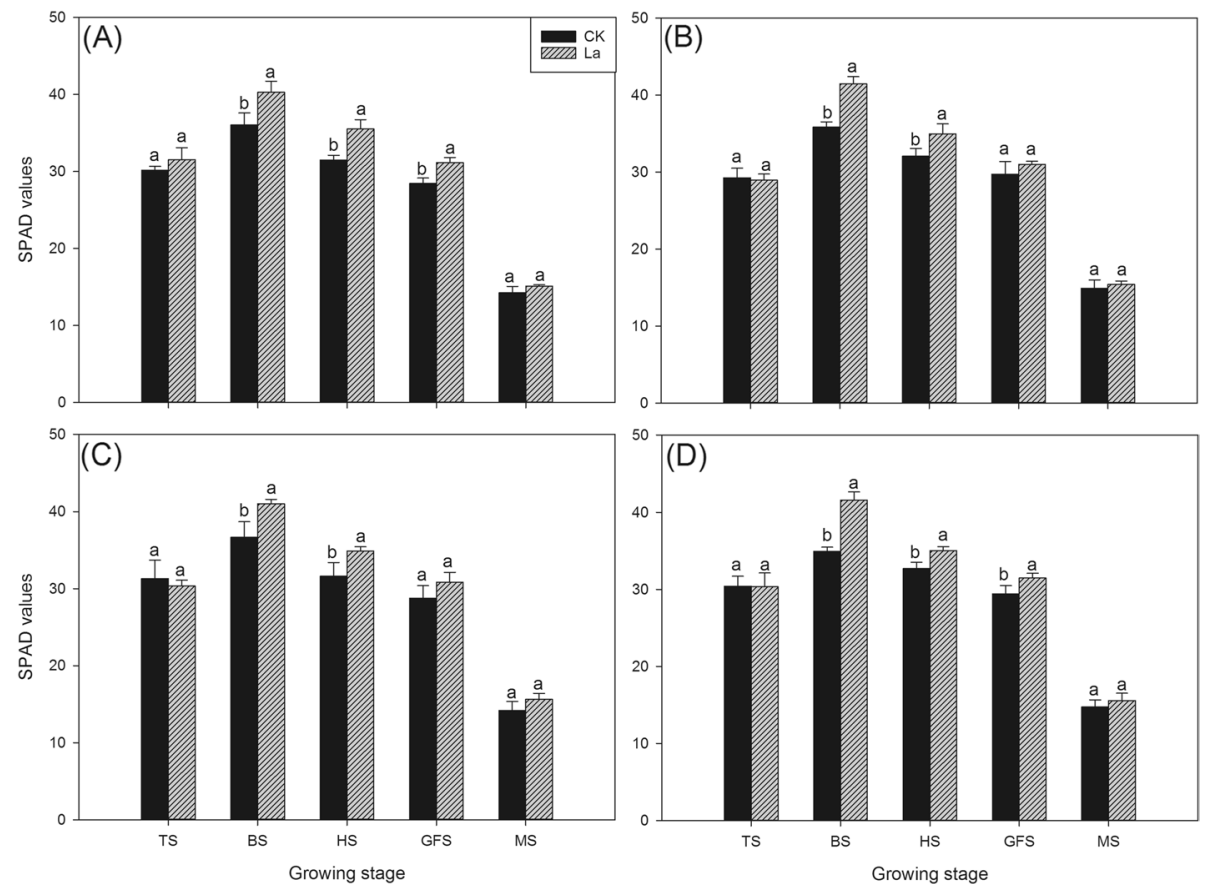

Fig. 3 Effects of different La treatments on the SPAD values of aromatic rice in the third experiment. a Meixiangzhan in 2018; b Xiangyaxiangzhan in 2018; c Meixiangzhan in 2019; d Xiangyaxiangzhan in 2019. TS: tillering stage; BS: booting stage: HS: heading stage: GFS: grain-filling stage; MS: Maturity stage. Values (means $\pm S E s)$ of each treatment were obtained from three independent replications $(n=3)$. Different letters indicate significant differences among the treatments $(P<0.05$, least significant difference test) 

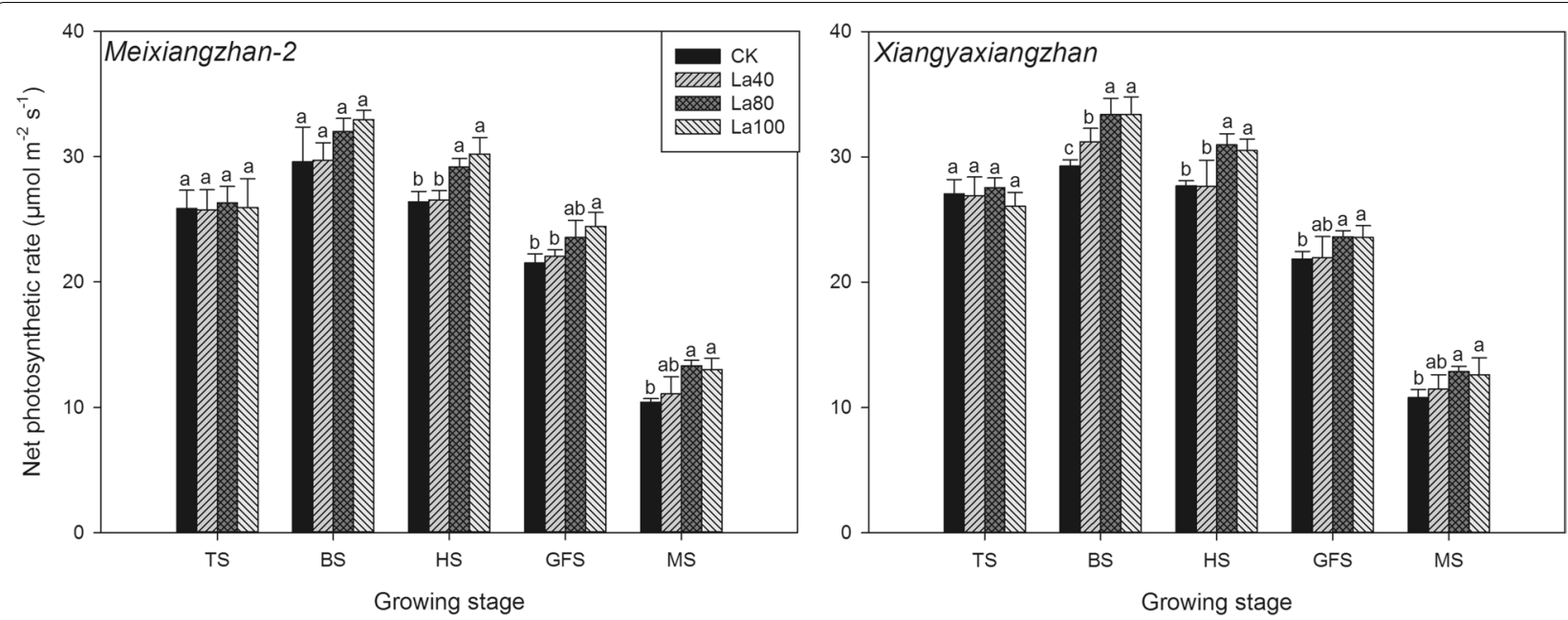

Fig. 4 Effects of different La treatments on the net photosynthetic rate of aromatic rice in the second experiment. TS: tillering stage; BS: booting stage: HS: heading stage: GFS: grain-filling stage; MS: Maturity stage. Values (means \pm SEs) of each treatment were obtained from three independent replications $(n=3)$. Different letters indicate significant differences among the treatments $(P<0.05$, least significant difference test)

Effects of La application on 2-AP content and 2-AP biosynthesis in aromatic rice

In the second experiment, aromatic rice plants grown in La containing soil showed higher grain 2-AP contents (Fig. 8, Fig. 9, Fig. 10 and Table 4). For Meixiangzhan-2, the La40, La80, and La100 treatments substantially increased the grain 2-AP contents by $12.61,27.53,26.72 \%$ compared with those in CK; For Xiangyaxiangzhan, 28.36, 37.62, and $43.03 \%$ higher 2-AP contents were recorded in the La40, La80, and La100 treatments than CK. As shown in Fig. 10, La application regulated 2-AP biosynthesis in terms of the proline, and GABA contents and, PDH and BADH activity. In comparison with CK, La80 and La100 treatments significantly reduced the
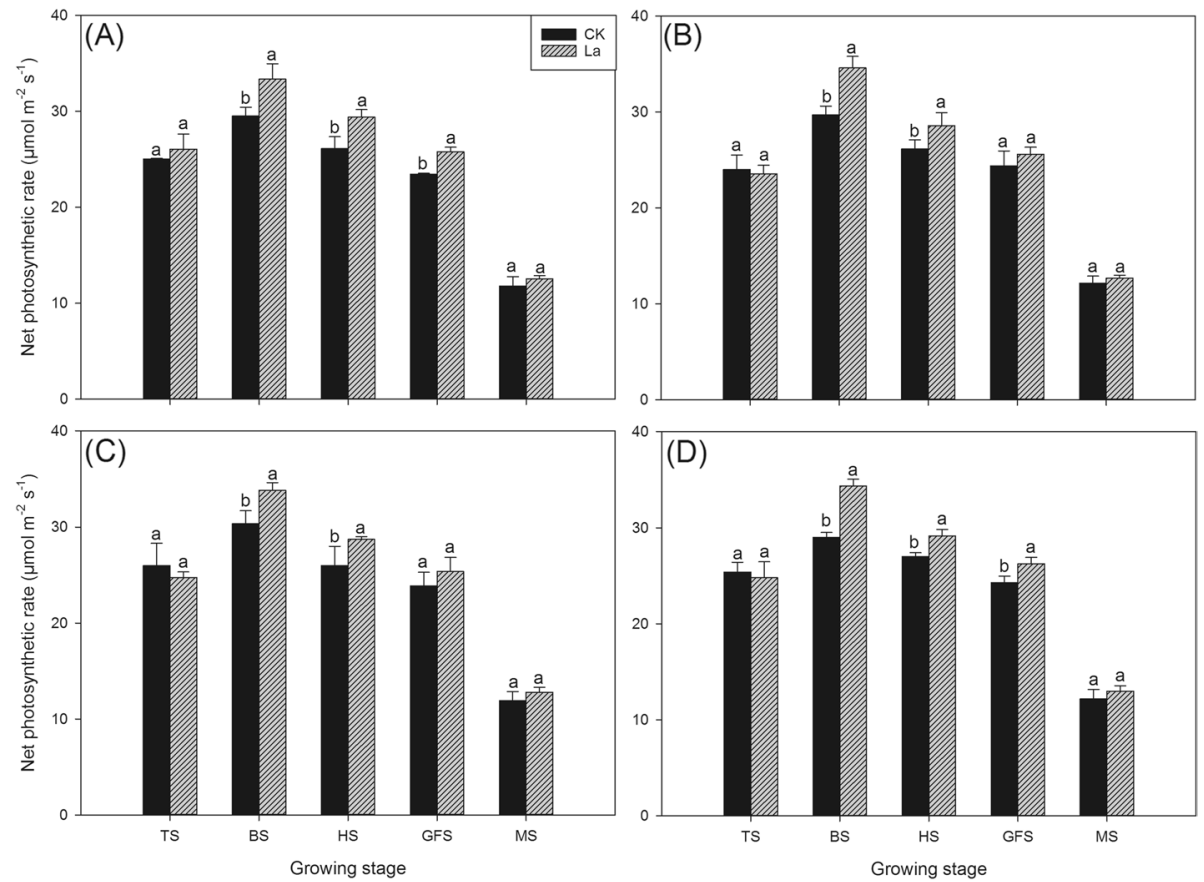

Fig. 5 Effects of different La treatments on the net photosynthetic rate of aromatic rice in the third experiment. a Meixiangzhan in 2018; b Xiangyaxiangzhan in 2018; c Meixiangzhan in 2019; d Xiangyaxiangzhan in 2019. TS: tillering stage; BS: booting stage: HS: heading stage: GFS: grain-filling stage; MS: maturity stage. Values (means $\pm S E s$ ) of each treatment were obtained from three independent replications $(n=3)$. Different letters indicate significant differences among the treatments $(P<0.05$, least significant difference test) 

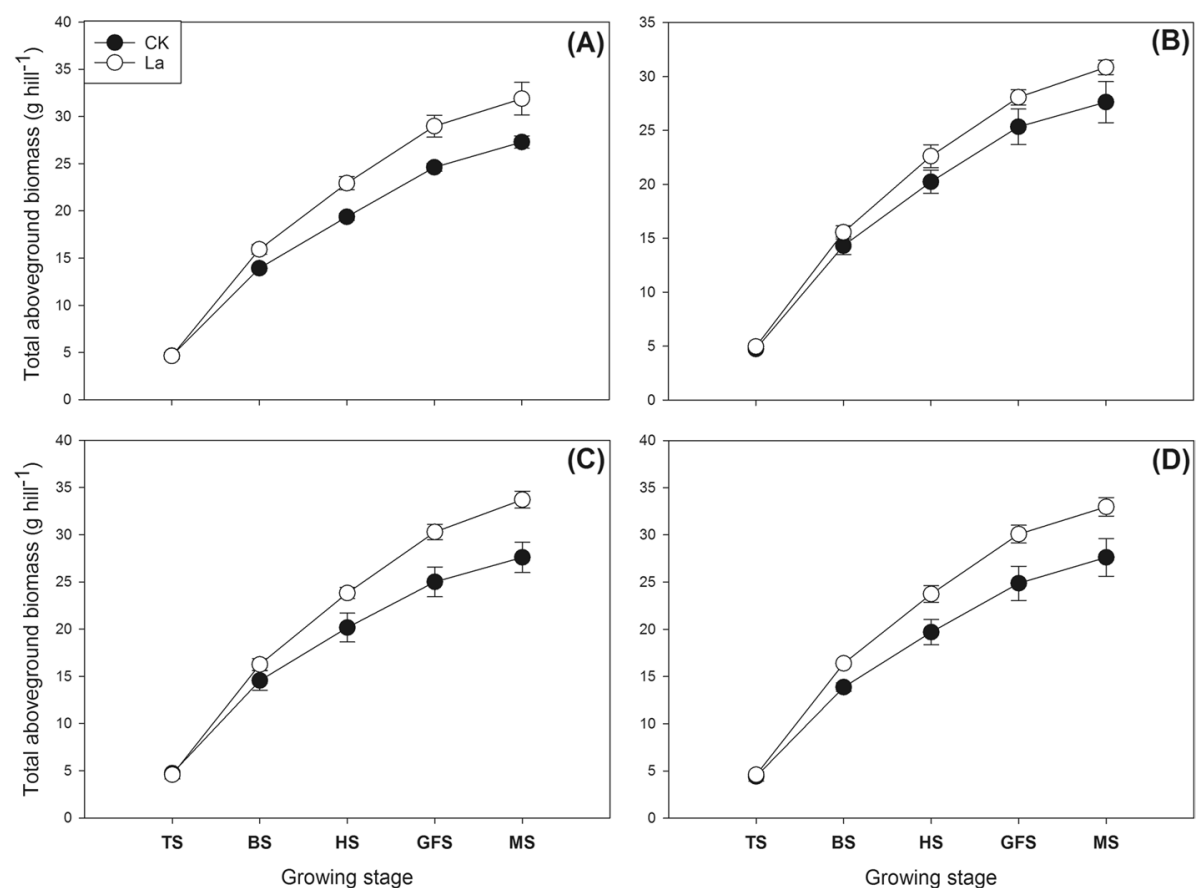

Fig. 6 Effects of La application on the total aboveground biomass of aromatic rice in the third experiment. a Meixiangzhan in 2018 ; b Xiangyaxiangzhan in 2018; c Meixiangzhan in 2019; d Xiangyaxiangzhan in 2019. TS: tillering stage; BS: booting stage: HS: heading stage: GFS: grain-filling stage; MS: maturity stage. Values (means \pm SEs) of each treatment were obtained from three independent replications $(n=3)$

grain contents of proline and GABA. Higher PDH activity was recorded in the La80 and La100 treatments than in CK. Lower BADH activity was recorded in the La80 and La100 treatments than in CK.

In the field production (the third Experiment), La application to the soil markedly increased the 2-AP content in aromatic rice grains (Fig. 9). In 2018, compared with CK, the La treatment significantly increased the grain 2-AP content by 31.36 and $32.85 \%$ in Meixiangzhan-2 and Xiangyaxiangzhan, respectively. In 2019, in comparison with CK, the La treatment significantly increased the grain 2-AP content by 28.55 and $23.08 \%$ in Meixiangzhan-2 and Xiangyaxiangzhan, respectively. As shown in Table 4, compared with $\mathrm{CK}$, the La treatment remarkably reduced the contents of proline and GABA, and the activity of BADH. Higher PDH activity was recorded in the La treatment than in CK.

\section{Discussion}

Crop growth and development are substantially affected by La, this has been previously reported in several plant species, such as wheat (Triticum aestivum L.), maize (Zea mays L.) and soybean (Glycine max (Linn.) Merr.) [16-18]. The current study demonstrated the modulatory effects of La application to soil on 2-AP biosynthesis in aromatic rice. In the first experiment, we observed that aromatic rice seedlings grown in La containing soil (80 and $100 \mathrm{LaCl}_{3} \mathrm{mg} \mathrm{kg}^{-1}$ ) not only had higher fresh weight, dry weight, plant height and stem length, but also had higher 2-AP contents than those grown in soil without La. In both the second and third experiments, the La treatments also substantially increased the grain yield of the aromatic rice cultivars. The increment in grain yield due to La application was attributed to improvement in grain number per panicle and seed-setting rate. Our results were consistent with the study of [19] who demonstrated that exogenous La significantly increased rice yield. As the method of dry matter accumulation in plants, photosynthesis was significantly influenced by La application in terms of the chlorophyll content and net photosynthetic rate in aromatic rice. The results of the present study showed that La treatments remarkably increased SPAD values and enhanced the net photosynthetic rate of the aromatic rice cultivars, Meixiangzhan-2 and Xiangyaxiangzhan at the booting stage, heading stage, grain-filling stage and maturity stage. The total aboveground biomass at the booting stage, heading stage, grain-filling stage and maturity stage (total yield) also increased due to La application. Therefore, we deduced that La enhanced yield formation in aromatic rice by regulating photosynthesis and dry matter accumulation.

In our study, higher activities of antioxidant enzymes (SOD, POD, CAT) and lower MDA content were observed in aromatic rice under the La treatments. Previous studies indicated the important roles of SOD, POD 


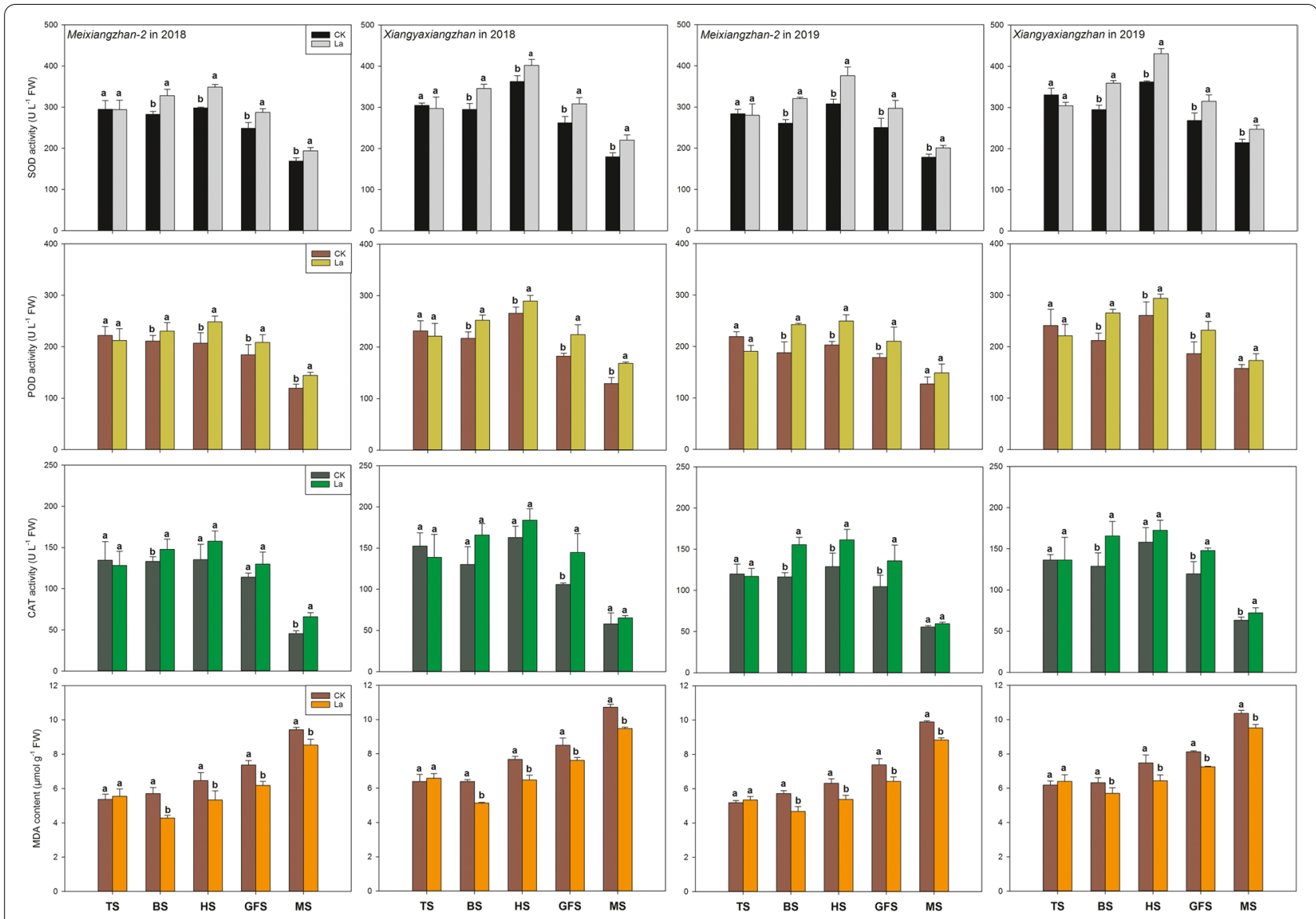

Fig. 7 Effects of La application on the activities of SOD, POD, and CAT and the contents of MDA in aromatic rice in the third experiment. TS: tillering stage; BS: booting stage: HS: heading stage: GFS: grain-filling stage; MS: maturity stage. Values (means \pm SEs) of each treatment were obtained from three independent replications $(n=3)$. Different letters indicate significant differences among the treatments $(P<0.05$, least significant difference test)

and CAT play in maintaining cellular structures and functions, and quenching reactive oxygen species in plant tissues [20, 21]. These enhancements in antioxidant activity indicated that La might improve ability of aromatic rice to resist different abiotic stresses. In the field, variations in climate especially the sudden occurrence of short-term extreme weather, have substantial effects on rice yield [22]. Moreover, the microclimate in paddy fields which is complicated and difficult to measure, also influences yield formation of rice [23]. A stronger antioxidant system in rice ensures stable rice production stabilization. Furthermore, chlorophyll biosynthesis and gas exchange for photosynthesis are affected by the environment $[20,24]$ while higher antioxidant enzyme activity can better maintain the stability of cells and ensure the progress of various physiological activities [25, 26]. Therefore, we deduced that the application of La might protect chlorophyll biosynthesis in aromatic rice by increasing the activities of antioxidant enzymes and that this would enhance photosynthesis and dry matter accumulation and finally increase grain yield.

Regarding 2-AP, a key component of the aroma of aromatic rice, the La treatments increased the grain 2-AP content and decreased the grain proline content in the second experiment. A similar result was also observed in the La treatment in the third experiment. Furthermore, the results of both the second and third experiments showed that the activity of PDH was significantly enhanced in the La treatments; this result is similar to the research of Mo et al. [10], who indicated that the additional La in culture medium increased the activity of PDH and the 2-AP content in aromatic rice panicles in vitro. The function of PDH is to catalyze the oxidation reaction of proline to convert $\triangle 1$-pyrroline-5-carboxylic acid, which is an important precursor for 2-AP biosynthesis $[27,28]$. Therefore, the increase in grain 2-AP content in aromatic rice could be attributed to exogenous $\mathrm{La}$ enhancing PDH activity and thus leading to the promotion of the conversion from proline to 2-AP. 


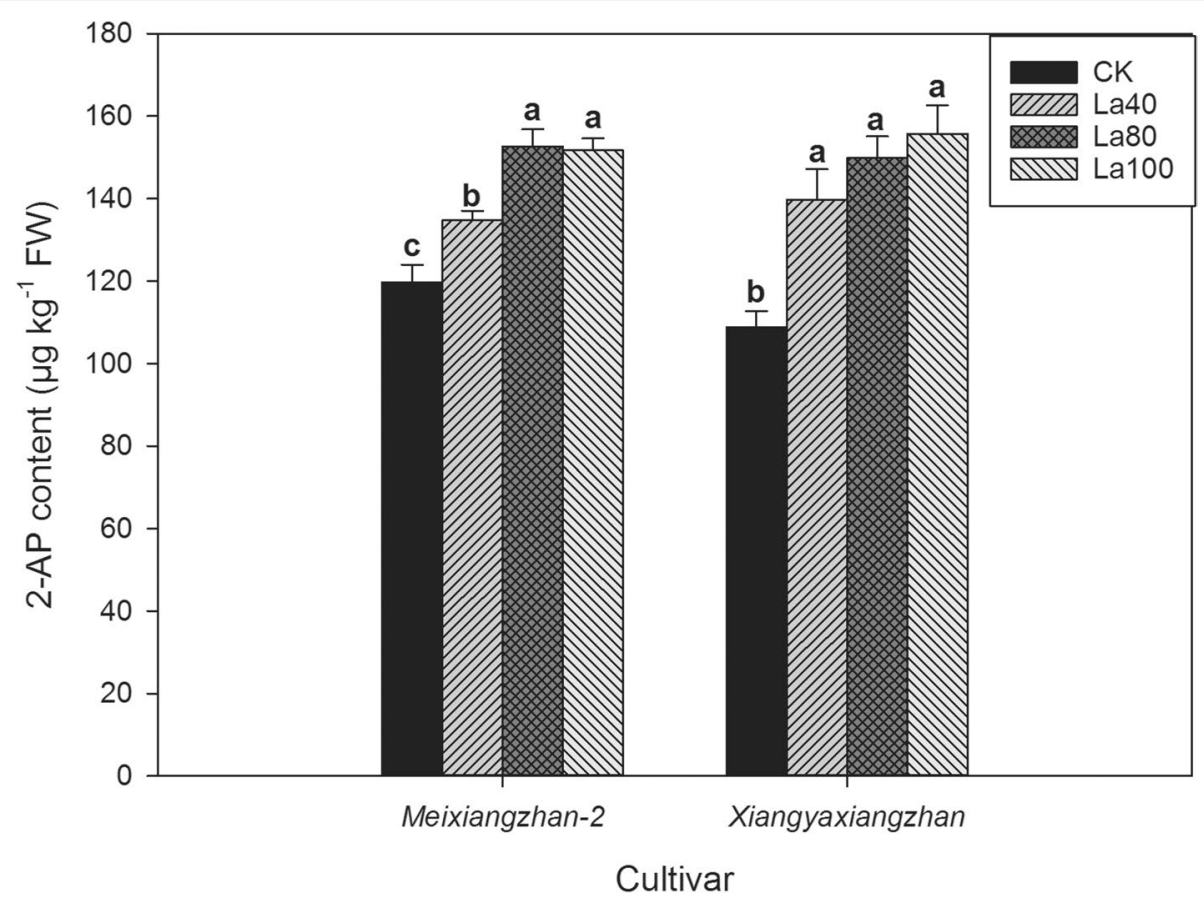

Fig. 8 Effects of different La treatments on the 2-AP content of aromatic rice in the second experiment. Values (means \pm SEs) of each treatment were obtained from three independent replications $(n=3)$. Different letters indicate significant differences among the treatments $(P<0.05$, least significant difference test)

In addition, the present study revealed that lower grain proline and GABA contents were recorded in the La treatments than in CK in both the second and third experiments. In 2-AP biosynthesis in aromatic rice, a competitive relationship exists between GABA and 2-AP and the conversion from GABald to $\triangle 1$-pyrroline (a limited substrate in 2-AP formation [6]) or GABA depends on the reaction catalyzed by the enzyme BADH $[9,29,30]$. The results of the second and third experiments showed that the activity of BADH declined under the La treatments. Therefore, we deduced that exogenous La also increases the conversion from GABald to $\triangle 1$-pyrroline by inhibiting GABA formation, thus increasing the 2-AP content in aromatic rice. The
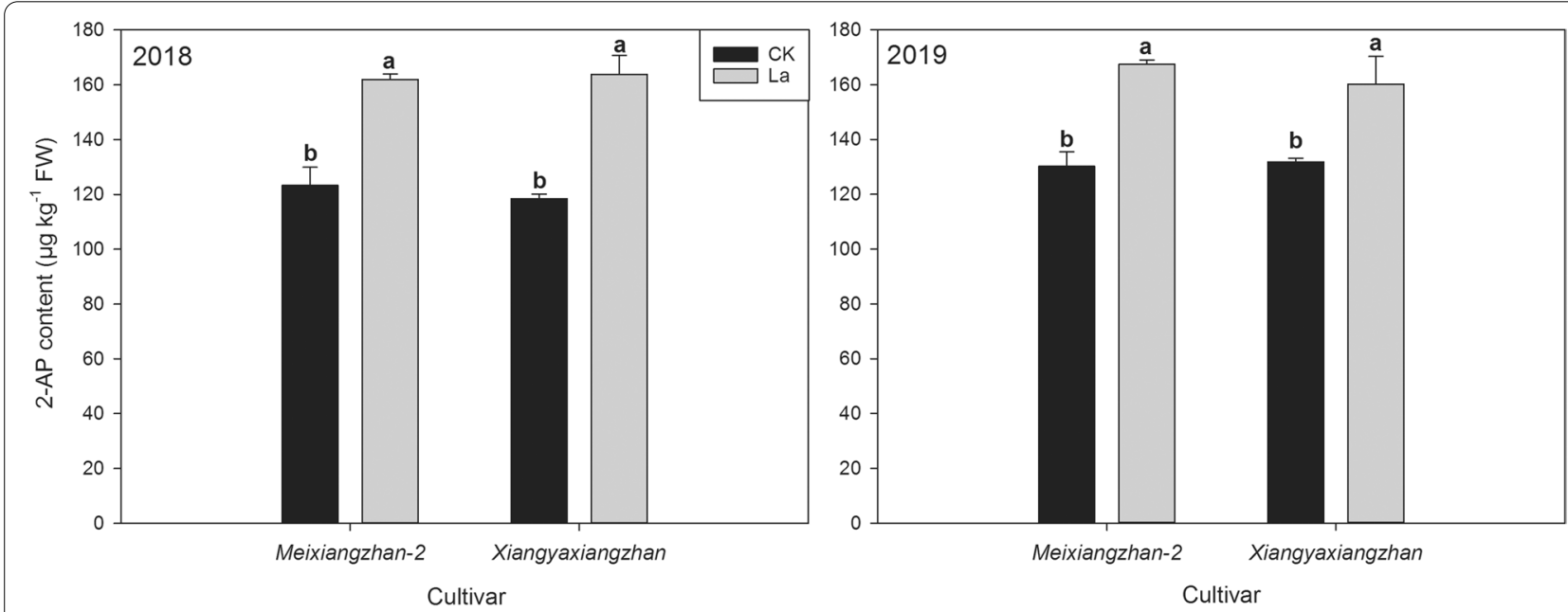

Fig. 9 Effects of La application on the 2-AP content of aromatic rice grains in the third experiment. Values (means \pm SEs) of each treatment were obtained from three independent replications $(n=3)$. Different letters indicate significant differences among the treatments $(P<0.05$, least significant difference test) 

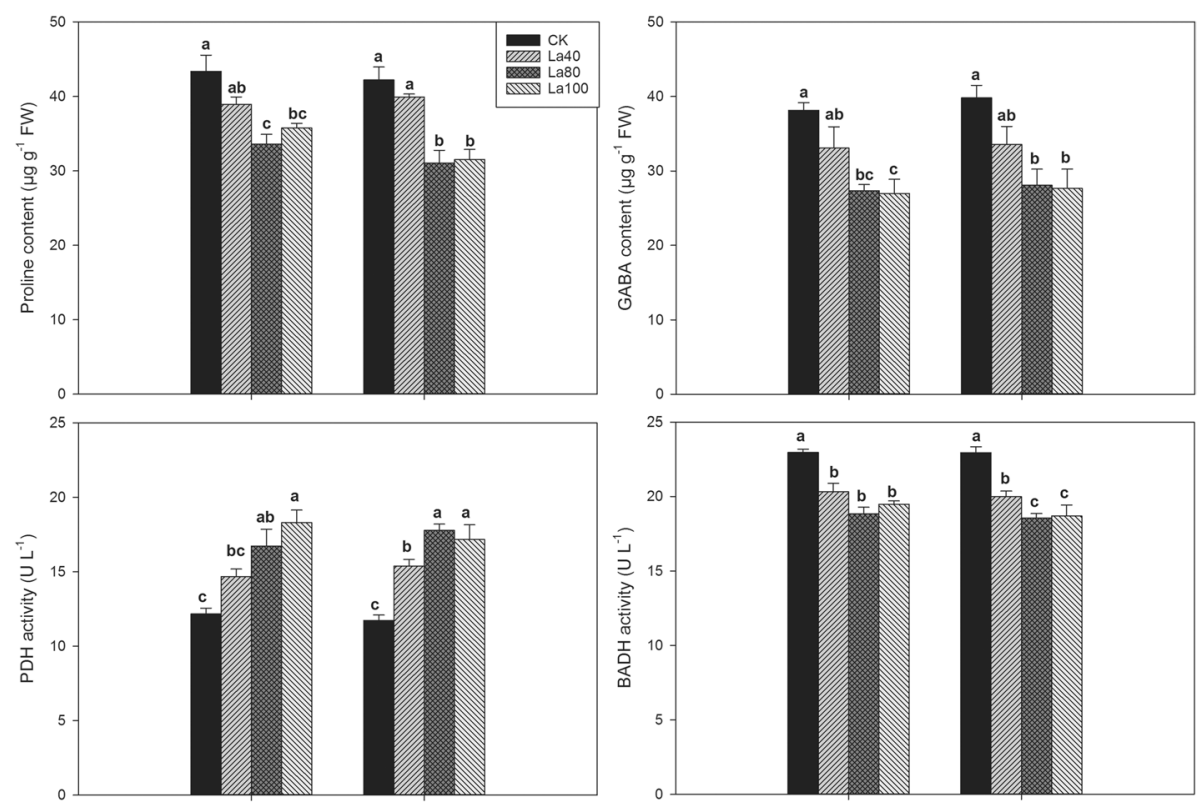

Fig. 10 Proline content, GABA content, PDH activity and BADH activity of aromatic rice under La application in the second experiment. Values (means $\pm S E s$ ) of each treatment were obtained from three independent replications $(n=3)$. Different letters indicate significant differences among the treatments $(P<0.05$, least significant difference test)

possible mechanism for the regulation of grain 2-AP biosynthesis in aromatic rice by exogenous La is shown in Fig. 11.

\section{Conclusion}

The application of La to soil increased the chlorophyll content and antioxidant enzyme activities of aromatic rice. Increases in the net photosynthetic rate, dry matter accumulation and yield formation were observed in the La treatments. La application also improved the conversion from proline to 2-AP by upregulating the activity of the enzyme PDH and thus increased the grain 2-AP content. In addition, La application inhibited BADH activity and thus reduced the conversion of GABald to GABA during 2-AP biosynthesis in aromatic rice.

Table 4 Proline content, GABA content, PDH activity and BADH activity of aromatic rice under La application in the field in the third experiment

\begin{tabular}{|c|c|c|c|c|c|c|}
\hline Year & Cultivar & Treatment & Proline $\left(\mu \mathrm{g} \mathrm{g}^{-1} \mathrm{FW}\right)$ & GABA $\left(\mu \mathrm{g} \mathrm{g}^{-1} \mathrm{FW}\right)$ & PDH activity (U L $\left.{ }^{-1} \mathrm{FW}\right)$ & $\begin{array}{l}\text { BADH } \\
\text { activity (U } \\
\left.\mathrm{L}^{-1} \mathrm{FW}\right)\end{array}$ \\
\hline \multirow[t]{6}{*}{2018} & \multicolumn{6}{|c|}{ Meixiangzhan-2 } \\
\hline & & CK & $43.14 \pm 1.37 a$ & $32.19 \pm 1.52 \mathrm{a}$ & $13.45 \pm 0.67 b$ & $22.48 \pm 0.35 a$ \\
\hline & & La & $34.12 \pm 0.43 b$ & $25.63 \pm 1.10 b$ & $17.58 \pm 0.72 \mathrm{a}$ & $18.54 \pm 0.43 b$ \\
\hline & \multicolumn{6}{|c|}{ Xiangyaxiangzhan } \\
\hline & & CK & $40.59 \pm 0.62 \mathrm{a}$ & $35.73 \pm 1.15 a$ & $13.46 \pm 1.15 b$ & $21.01 \pm 0.45 a$ \\
\hline & & La & $31.19 \pm 0.53 b$ & $28.08 \pm 1.71 b$ & $18.27 \pm 1.07 a$ & $17.13 \pm 0.84 b$ \\
\hline \multirow[t]{6}{*}{2019} & \multicolumn{6}{|c|}{ Meixiangzhan-2 } \\
\hline & & CK & $41.98 \pm 0.84 a$ & $34.51 \pm 0.23 a$ & $12.04 \pm 0.91 b$ & $21.51 \pm 0.39 a$ \\
\hline & & La & $33.21 \pm 1.20 b$ & $24.12 \pm 1.57 b$ & $18.89 \pm 1.27 a$ & $17.39 \pm 0.59 b$ \\
\hline & \multicolumn{6}{|c|}{ Xiangyaxiangzhan } \\
\hline & & CK & $43.31 \pm 2.67 a$ & $39.16 \pm 1.28 a$ & $13.23 \pm 1.09 b$ & $20.99 \pm 0.28 a$ \\
\hline & & La & $32.77 \pm 1.71 b$ & $25.89 \pm 2.54 b$ & $16.40 \pm 0.32 a$ & $18.59 \pm 0.25 b$ \\
\hline
\end{tabular}

Values (means $\pm S E s$ ) of each treatment were obtained from three independent replications $(n=3)$. Different letters indicate significant differences among the treatments $(P<0.05$, least significant difference test) 


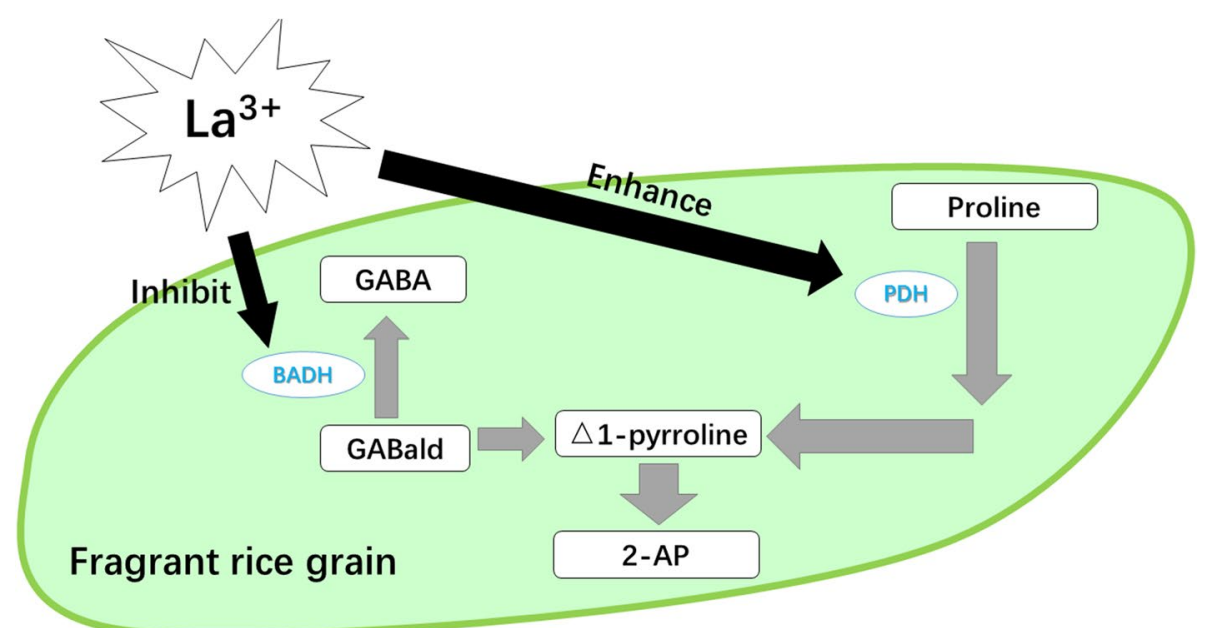

Fig. 11 The potential roles of exogenous La in regulation of 2-AP biosynthesis in aromatic rice plants

\section{Methods}

\section{Experimental details and plant materials}

To study the effect of La on 2-AP biosynthesis in aromatic rice, three experiments (two pot experiments and a twoyear field experiment) were conducted with two aromatic rice cultivars, Meixiangzhan-2 (Lemont $\times$ Fengaozhan) and Xiangyaxiangzhan (Xiangsimiao126 $\times$ Xiangyaruanzhan). These cultivars are widely planted in South China, and were provided by the College of Agriculture, South China Agricultural University, Guangzhou, China. Detailed information on the varieties could be found at https://ricedata.cn/. The three experiments were performed as described below:

The first experiment was conducted at the College of Agriculture, South China Agricultural University, Guangzhou, China between October and December 2017. After soaking and germination, the seeds of aromatic rice were sown in plastic pots $(14.5 \mathrm{~cm}$ upper diameter, $10.5 \mathrm{~cm}$ lower diameter and $7.5 \mathrm{~cm}$ height) filled with paddy soil. There were five La treatments i.e., La1: $20 \mathrm{mg} \mathrm{kg}^{-1} \mathrm{LaCl}_{3}$; La2: $40 \mathrm{mg} \mathrm{kg} \mathrm{LaCl}_{3}$; La3: $80 \mathrm{mg} \mathrm{kg} \mathrm{kaCl}_{3}$; La4: $100 \mathrm{mg} \mathrm{kg}{ }^{-1} \mathrm{LaCl}_{3}$; and La5: $120 \mathrm{mg} \mathrm{kg}{ }^{-1} \mathrm{LaCl}_{3}$. Pots without applied La were used as controls (CK). Twenty days after sowing, the seedlings were collected and the fresh weight, dry weight, plant height, stem diameter and 2-AP content were determined.

The second experiment was conducted in the greenhouse of the Experimental Research Farm, College of Agriculture, South China Agricultural University, Guangzhou, China $\left(23^{\circ} 09^{\prime} \mathrm{N}, 113^{\circ} 22^{\prime} \mathrm{E}\right.$ and $11 \mathrm{~m}$ above the sea level) between March and July 2018. The germinated seeds of aromatic rice were sown in soils contained in plastic nursery trays. When the seedlings were twenty days old, they were transplanted into pots with five hills per pot $(32 \mathrm{~cm}$ upper diameter, $21 \mathrm{~cm}$ lower diameter and $23 \mathrm{~cm}$ height) and four seedlings per hill. According to the results of the first experiment, three La treatments were implemented, i.e., La40: $40 \mathrm{mg} \mathrm{kg}^{-1}$ $\mathrm{LaCl}_{3}$; La80: $80 \mathrm{mg} \mathrm{kg}^{-1} \mathrm{LaCl}_{3}$; and La100: $100 \mathrm{mg} \mathrm{kg}^{-1}$ $\mathrm{LaCl}_{3}$. Pots without $\mathrm{La}$ application were used as the controls (CK). At the grain-filling and maturity stages, fresh panicles were collected and stored at $-80{ }^{\circ} \mathrm{C}$ for biochemical and molecular analysis. The grain yield and yield-related traits of aromatic rice were also estimated at the maturity stage.

The third experiment was conducted at the Experimental Research Farm, South China Agricultural University, Ningxi County $\left(23^{\circ} 16^{\prime} \mathrm{N}, 113^{\circ} 22^{\prime} \mathrm{E}\right.$ and $11 \mathrm{~m}$ above sea level), Guangdong Province, China between July and November in 2018 and again in 2019. After germination in the nursery, fifteen-day-old seedlings were mechanically transplanted into paddy fields at a planting distance of $30 \mathrm{~cm} \times 16 \mathrm{~cm}$. According to the results from both the first experiment and the second experiment, the La treatment was set as $12 \mathrm{~kg} \mathrm{ha}^{-1}$ $\mathrm{LaCl}_{3}$, and a treatment without La application was used as a control (CK). The treatments were arranged in a randomized complete block design (RCBD) in triplicate with a total plot size of $10 \mathrm{~m} \times 3 \mathrm{~m}$. At the tillering stage (20 days after transplanting), booting stage (40 days after transplanting), heading stage (60 days after transplanting), grain-filling stage (75 days after transplanting) and maturity stage (90 days after transplanting, also 1 day before harvesting), fresh flag leaves from each plot were collected and stored at $-80^{\circ} \mathrm{C}$. At the grain-filling stage and maturity stage, fresh panicles were also collected and stored at $-80^{\circ} \mathrm{C}$ for biochemical analysis. The grain yield and yield related traits of aromatic rice were also estimated at the maturity stage. 
Determination of net photosynthetic rate, chlorophyll content and dry matter accumulation

At the tillering stage (20 days after transplanting), booting stage (40 days after transplanting), heading stage (60 days after transplanting), grain-filling stage (75 days after transplanting) and maturity stage (90 days after transplanting, also 1 day before harvesting) in the second and third experiments, the net photosynthetic rate was determined with the portable photosynthesis system (LI-6400, LI-COR, USA) according to the method described by Luo et al. (2019). At the same time, a 'SPAD-502' SPAD meter (Konica Minolta, Japan) was used to perform a precise, rapid and nondestructive estimation of the leaf chlorophyll contents. In the second experiment, the total aboveground tissue of aromatic rice from three random pots in each treatment was collected at the maturity stage and oven-dried at $80{ }^{\circ} \mathrm{C}$ for the determination of the total yield. In the third experiment, plants from 9 randomly selected hills were collected at the tillering stage, booting stage, heading stage, grain-filling stage and maturity stage and oven-dried at $80{ }^{\circ} \mathrm{C}$ to a constant weight for the determination of the total aboveground biomass.

\section{Determination of activities of superoxide (SOD), peroxidase (POD), catalase (CAT) and contents of malondialdehyde (MDA)}

The MDA content and activities of antioxidant enzymes in the leaves of aromatic rice were determined according to the methods described by Kong et al. [20]. The MDA content was detected after a reaction with thiobarbituric acid while the absorbance was read at $532 \mathrm{~nm}, 600 \mathrm{~nm}$ and $450 \mathrm{~nm}$. The activities of SOD, POD and CAT were determined and expressed as $\mathrm{U} \mathrm{L}^{-1} \mathrm{FW}$.

\section{Determination of 2-AP content}

The 2-AP contents in the grain samples collected at maturity and the seedling samples were determined using the simultaneous distillation-extraction method (SDE) and analyzed by a GCMS-QP 2010 Plus (Shimadzu Corporation, Japan) according to the methods of [31].

\section{Determination of the contents of proline and GABA, and activities of PDH and BADH}

The contents of proline and GABA in the grain samples collected at the grain-filling stage were determined according to the methods described by Mo et al. [4]. The proline content was determined after reacting with sulfosalicylic acid and the absorbance was measured at $520 \mathrm{~nm}$. The GABA in the samples was extracted using
$60 \%$ ethanol, and the absorbance was read at $645 \mathrm{~nm}$. The GABA content was expressed as $\mu \mathrm{g} \mathrm{g}^{-1} \mathrm{FW}$. The activities of PDH and BADH in grains at the grain-filling stage were estimated according to the methods of Luo et al. [2]. For BADH activity, the absorbance was read at $450 \mathrm{~nm}$ and expressed as $\mathrm{U} \mathrm{L}^{-1}$. For PDH activity, the absorbance was read at $440 \mathrm{~nm}$ and expressed as $\mathrm{UL}^{-1}$.

\section{Statistical analyses}

All data were analyzed statistically using Statistix 8 (Analytical software, Tallahassee, Florida, USA) with one-way analysis of variance. The differences among means were separated by using the least significant difference (LSD) test at the $5 \%$ significance level.

\section{Abbreviations \\ 2-AP: 2-Acetyl- $\triangle 1$-pyrroline; BADH: Betaine aldehyde dehydrogenase; CAT: Catalase; GABA: $\gamma$ - Aminobutyric acid; La: Lanthanum; MDA: Malondialdehyde; PDH: Proline dehydrogenase; POD: Peroxidase; SOD: Superoxide dismutase.}

\section{Acknowledgements}

Not applicable

\section{Authors' contributions}

$\mathrm{HL}$ and $\mathrm{XT}$ planned and designed the research; $\mathrm{YC}$ and LH performed the experiments; $\mathrm{HL}$ wrote the first version of manuscript. XT provided the guidance during the experiment and paper writing. All authors have read and approved the final manuscript.

\section{Funding}

This study was funded by National Natural Science Foundation of China under Grant 31971843; and Technology System of Modern Agricultural Industry in Guangdong under Grant 2019KJ105.

Availability of data and materials

All data generated or analysed during this study are included in this published article.

\section{Declarations}

Ethics approval and consent to participate

Not applicable.

Consent for publication

Not applicable.

\section{Competing interests}

The authors declare that they have no competing interests.

\section{Author details \\ ${ }^{1}$ State Key Laboratory for Conservation and Utilization of Subtropical Agro-Bioresources, College of Agriculture, South China Agricultural University, Guangzhou 510642, China. ${ }^{2}$ Scientific Observing and Experimental Station of Crop Cultivation in South China, Ministry of Agriculture and Rural Affairs, Guangzhou 510642, China. ${ }^{3}$ Guangzhou Key Laboratory for Science and Tech- nology of Aromatic Rice, Guangzhou 510642, China. ${ }^{4}$ The College of Natural Resources and Environment, College of Agriculture, South China Agricultural University, Guangzhou 510642, China.}

Received: 16 February 2021 Accepted: 3 May 2021

Published online: 25 May 2021 


\section{References}

1. Liu X, Huang Z, Li Y, Xie W, Li W, Tang X, Ashraf U, Kong L, Wu L, Wang S, et al. Selenium-silicon (Se-Si) induced modulations in physio-biochemical responses, grain yield, quality, aroma formation and lodging in fragrant rice. Ecotox Environ Safe. 2020;196:110525.

2. Luo H, He L, Du B, Pan S, Mo Z, Duan M, Tian H, Tang X. Biofortification with chelating selenium in fragrant rice: Effects on photosynthetic rates, aroma, grain quality and yield formation. Field Crop Res. 2020;255:107909.

3. Xie W, Kong L, Ma L, Ashraf U, Pan S, Duan M, Tian H, Wu L, Tang X, Mo Z. Enhancement of 2-acetyl-1-pyrroline (2AP) concentration, total yield, and quality in fragrant rice through exogenous $\gamma$-aminobutyric acid (GABA) application. J Cereal Sci. 2020;91:102900.

4. Mo Z, Li W, Pan S, Fitzgerald TL, Xiao F, Tang Y, Wang Y, Duan M, Tian $H$, Tang $X$. Shading during the grain filling period increases 2-acetyl1-pyrroline content in fragrant rice. Rice. 2015;8:9.

5. Champagne El. Rice aroma and flavor: A literature review. Cereal Chem. 2008:85(4):447-56.

6. Poonlaphdecha J, Gantet P, Maraval I, Sauvage F, Menut C, Morère A, Boulanger R, Wüst M, Gunata Z. Biosynthesis of 2-acetyl-1-pyrroline in rice calli cultures: Demonstration of 1-pyrroline as a limiting substrate. Food Chem. 2016;197:965-71.

7. Wakte K, Zanan R, Hinge V, Khandagale K, Nadaf A, Henry R. Thirtythree years of 2-acetyl-1-pyrroline, a principal basmati aroma compound in scented rice ( Oryza sativa L.): a status review. J Sci Food Agr. 2017;97(2):384-95

8. Yoshihashi T, Huong NTT, Inatomi H. Precursors of 2-Acetyl-1-pyrroline, a Potent Flavor Compound of an Aromatic Rice Variety. J Agr Food Chem. 2002;50(7):2001-4.

9. Chen S, Yang Y, Shi W, Ji Q, He F, Zhang Z, Cheng Z, Liu X, Xu M. Badh2, Encoding Betaine Aldehyde Dehydrogenase, Inhibits the Biosynthesis of 2-Acetyl-1-Pyrroline, a Major Component in Rice Fragrance. Plant Cell. 2008;20(7):1850-61.

10. Mo Z, Huang J, Xiao D, Ashraf U, Duan M, Pan S, Tian H, Xiao L, Zhong K, Tang X. Supplementation of 2-Ap, Zn and La Improves 2-Acetyl1-Pyrroline Concentrations in Detached Aromatic Rice Panicles In Vitro. PLoS One. 2016;11(2):e149523.

11. Si Y, Wang L, Zhou Q, Huang X. Effects of lanthanum and silicon stress on bio-sequestration of lanthanum in phytoliths in rice seedlings. Environ Sci Pollut R. 2018:25(11SI):10752-70.

12. Zhong Y, Chen J. Ameliorative effects of Lanthanum(III) on Copper(II) stressed rice (Oryza sativa) and its molecular mechanism revealed by transcriptome profiling. Plant Physiol Bioch. 2020;152:184-93.

13. Liang C, Li L, Su L. Effect of Lanthanum on Plasma Membrane H+ATPase in Rice (Oryza sativa) Under Acid Rain Stress. J Plant Growth Regul. 2018;37(2):380-90.

14. Liu $D$, Zheng $S$ Wang $X$ : Lanthanum regulates the reactive oxygen species in the roots of rice seedlings. SCI REP-UK 2016, 6(31860)

15. Wang L, Wang W, Zhou Q, Huang X. Combined effects of lanthanum (III) chloride and acid rain on photosynthetic parameters in rice. Chemosphere. 2014:112:355-61.

16. Huang G, Wang L, Zhou Q. Lanthanum (III) Regulates the Nitrogen Assimilation in Soybean Seedlings under Ultraviolet-B Radiation. Biol Trace Elem Res. 2013;151(1):105-12.

17. Liu RQ, Xu XJ, Wang S, Shan CJ. Lanthanum improves salt tolerance of maize seedlings. Photosynthetica. 2016;54(1):148-51.

18. Zhang ZY, Li FL, Xu L, Liu N, Xiao HQ, Chai ZF. Study of binding properties of lanthanum to wheat roots by INAA. J Radioanal Nucl Ch. 2004;259(1):47-9.

19. Xie ZB, Zhu JG, Chu HY, Zhang YL, Zeng Q, Cao ZH. Influence of lanthanum on phosphorus uptake and its chemical fractions in rice crop Oryza sativa. J Rare Earth. 2003;21(2):180-4.

20. Kong L, Ashraf U, Cheng S, Rao G, Mo Z, Tian H, Pan S, Tang X. Shortterm water management at early filling stage improves early-season rice performance under high temperature stress in South China. Eur J Agron. 2017:90:117-26.

21. Ashraf U, Kanu AS, Deng Q, Mo Z, Pan S, Tian H, Tang X: Lead (Pb) Toxicity; Physio-Biochemical Mechanisms, Grain Yield, Quality, and Pb Distribution Proportions in Scented Rice. Front Plant Sci 2017, 8:259
22. Wang W, Yuan S, Wu C, Yang S, Zhang W, Xu Y, Gu J, Zhang H, Wang Z, Yang J et al: Field experiments and model simulation based evaluation of rice yield response to projected climate change in Southeastern China. Scie Total Environ 2020:143206

23. Yang G, Guo Z, Ji H, Sheng J, Chen L, Zhao Y. Application of insectproof nets in pesticide-free rice creates an altered microclimate and differential agronomic performance. Peer J. 2018;6:e6135.

24. He LX, Chen YL, Zhang TT, Zheng AX, Cheng Y, Du P, Lai RF, Lu RH, Luo HW, Liu YF, et al. Effects Of Different Temperature Conditions On Yield And Physiological Properties Of Rice (Oryza Sativa L.). Appl Ecol Env Res. 2019;17(1):199-211.

25. Zheng L, Ma Y, Zhang Y, Meng Q, Yang J, Wang B, Liu Q, Cai L, Gong W, Yang $Y$ et al: Increased antioxidant activity and improved structural characterization of sulfuric acid-treated stepwise degraded polysaccharides from Pholiota nameko PN-01. INT J Biol Macromol 2020

26. He D, Peng X, Xing Y, Wang Y, Zeng W, Su N, Zhang C, Lu D, Xing X. Increased stability and intracellular antioxidant activity of chlorogenic acid depend on its molecular interaction with wheat gluten hydrolysate. Food Chem. 2020;325:126873.

27. Li M, Ashraf U, Tian H, Mo Z, Pan S, Anjum SA, Duan M, Tang X. Manganese-induced regulations in growth, yield formation, quality characters, rice aroma and enzyme involved in 2-acetyl-1-pyrroline biosynthesis in fragrant rice. Plant Physiol Bioch. 2016;103:167-75.

28. Mo Z, Li Y, Nie J, He L, Pan S, Duan M, Tian H, Xiao L, Zhong K, Tang X: Nitrogen application and different water regimes at booting stage improved yield and 2-acetyl-1-pyrroline (2AP) formation in fragrant rice. Rice 2019, 12(1)

29. Li W, Zeng X, Li S, Chen F, Gao J. Development and application of two novel functionalmolecular markers of $\mathrm{BADH} 2$ in rice. Electron $J$ Biotechn. 2020;46:1-7.

30. Shao G, Tang S, Chen M, Wei X, He J, Luo J, Jiao G, Hu Y, Xie L, Hu P. Haplotype variation at Badh2, the gene determining fragrance in rice. Genomics. 2013;101(2):157-62.

31. Luo H, Liu J, Xing P, Lai R, Zhang T, Wang Z, He L, Tang X: Application of saline to seeds enhances the biosynthesis of 2-acetyl-1-pyrroline in aromatic rice seedlings (Oryza sativa L.). Acta Physiol Plant 2020, 42(6)

\section{Publisher's Note}

Springer Nature remains neutral with regard to jurisdictional claims in published maps and institutional affiliations. 